\title{
Neoplasias plasmocitárias em neurocirurgia: revisão da literatura e relatos de casos
}

\section{Plasmocytic Neoplasms in Neurosurgery: Literature Review and Reports of Cases}

\author{
Marcelo Lemos Vieira da Cunha ${ }^{1}$ Adir Bruno Serraglio ${ }^{2}$ Patricia Rauber ${ }^{2}$ Alana Becker ${ }^{2}$

\footnotetext{
${ }^{1}$ Neurocirurgião do Hospital Regional do Oeste, Chapecó, SC, Brasil; membro titular da Sociedade Brasileira de Neurocirurgia, São Paulo, SP, Brasil

${ }^{2}$ Acadêmico do curso de medicina da Universidade Comunitária Regional de Chapecó (Unochapecó), Chapecó, SC, Brasil
} \\ Address for correspondence Marcelo Lemos Vieira da Cunha, MD, \\ Departamento de Neurocirurgia do Hospital Regional do Oeste, rua \\ Rui Barbosa, 93-E, ap. 501, Centro, Chapecó, SC, Brasil CEP: 89801- \\ 040 (e-mail: marcelolvc@yahoo.com.br). \\ Departamento de Neurocirurgia do Hospital Regional do Oeste, \\ Chapecó, SC, Brasil.,
}

Arq Bras Neurocir 2015;34:237-240

\section{Resumo}

Palavras-Chave

- mieloma múltiplo

- plasmocitoma
O mieloma múltiplo (MM) é uma doença sistêmica maligna plasmocitária, caracterizada pela proliferação de um linfócito B clonal neoplásico, responsável por cerca de $2 \%$ de todas as mortes por câncer. Já o plasmocitoma solitário é um tumor localizado de células plasmocitárias. Relatamos dois casos de neoplasias plasmocitárias enfatizando as repercussões neurocirúrgicas.

Multiple myeloma (MM) is a malignant plasma cell systemic disease characterized by the proliferation of a clonal neoplastic B cell, responsible for $\sim 2 \%$ of all cancer deaths. The solitary plasmocytoma is a located tumor of plasma cells. We report two cases of malignancies plasmocytic emphasizing neurosurgical repercussions.

\section{Introdução}

A neoplasia de células plasmocitárias pode apresentar-se como lesão isolada (plasmocitoma) ou múltiplas lesões (mieloma múltiplo). ${ }^{1}$ Plasmocitomas são tumores compostos por plasmócitos com variáveis graus de maturação, histologicamente idênticos aos observados no mieloma múltiplo. ${ }^{2}$ Quando ocorrem nos ossos, são denominados plasmocitomas solitários ósseos, e nos tecidos moles são denominados plasmocitomas extramedulares. ${ }^{1-4} \mathrm{O}$ plasmocitoma solitário ósseo é caracterizado pela presença de um plasmocitoma na ausência de múltiplas lesões osteolíticas ou outros achados compatíveis com mieloma múltiplo. ${ }^{1}$ Apesar disso, cerca de $50-60 \%$ dos pacientes com plasmocitoma solitário ósseo vão desenvolver mieloma múltiplo em um período de 10 anos $^{1,2}-0$ plasmocitoma solitário ósseo tem risco significativamente maior para progressão ao mieloma em relação ao extramedular. ${ }^{3}$

received

May 1, 2015

accepted

June 12, 2015
DOI http://dx.doi.org/ 10.1055/s-0035-1559893. ISSN 0103-5355.
O mieloma múltiplo (MM) é uma doença sistêmica maligna plasmocitária de etiologia desconhecida, ${ }^{5}$ porém fatores genéticos, benzeno, doenças inflamatórias crônicas, terapia imunossupressora, doença autoimune e radiação parecem estimular o desenvolvimento da doença. ${ }^{6}$ Representa $1 \%$ de todas as neoplasias malignas, ${ }^{7,8}$ é considerado a segunda neoplasia hematológica mais frequente ${ }^{9,10}$ e é responsável por cerca de $2 \%$ de todas as mortes por câncer. ${ }^{11}$

\section{Relato dos Casos}

\section{Caso 1-Plasmocitoma solitário}

Paciente masculino, 67 anos, com surdez à esquerda há 6 meses (não mensurada por audiometria) e evolução com paralisia facial periférica à esquerda há 60 dias (HouseBreckmann V). Sem déficit de consciência, sem outras alterações ao exame físico neurológico. Tomografia computadorizada (TC) de crânio com lesão expansiva, ocupando toda a

Copyright $(2015$ by Thieme Publicações License terms Ltda, Rio de Janeiro, Brazil 


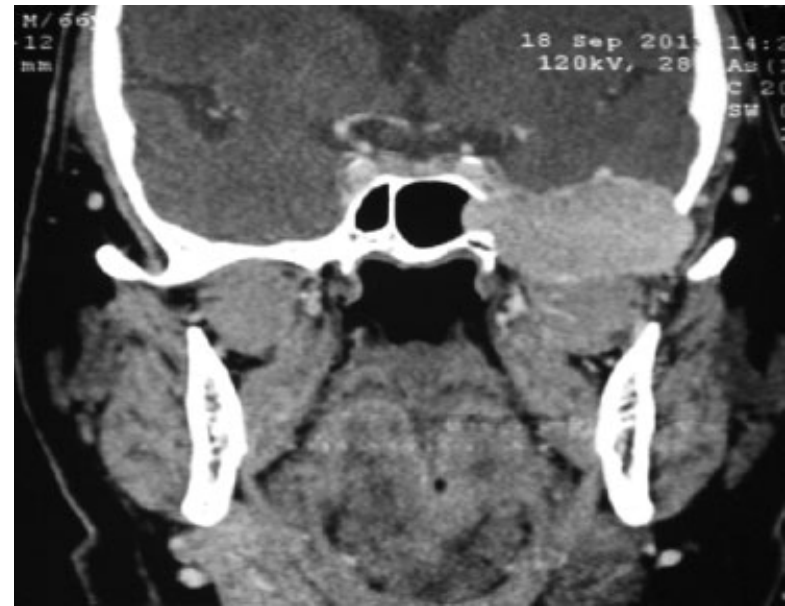

Fig. 1 TC de crânio com contraste, em corte coronal, evidenciando destruição da fossa média e invasão do seio esfenoidal.

fossa média craniana (-Fig. 1). Ressonância magnética (RM) de encéfalo com lesão hipercaptante. Submetido à ressecção ampla da lesão de base de crânio em fossa média sem novos déficits focais (-Fig. 2). Boa evolução pós-operatória com seguimento hematológico-quimioterápico.

\section{Caso 2-Mieloma múltiplo}

Paciente feminino, 66 anos, com histórico de queda da própria altura com cervicalgia à mobilização há 6 meses. TC cervical demonstrou fratura de C2 tipo IIb. Em seguimento ortopédico de forma conservadora, houve piora da instabilidade cervical culminada com perda motora. Após 15 dias de evolução, foi admitida no serviço com força motora de grau IV em membros inferiores e grau III em membros superiores. RM de coluna cervical com compressão medular (-Fig. 3). Realizada investigação de lesão metastática sem

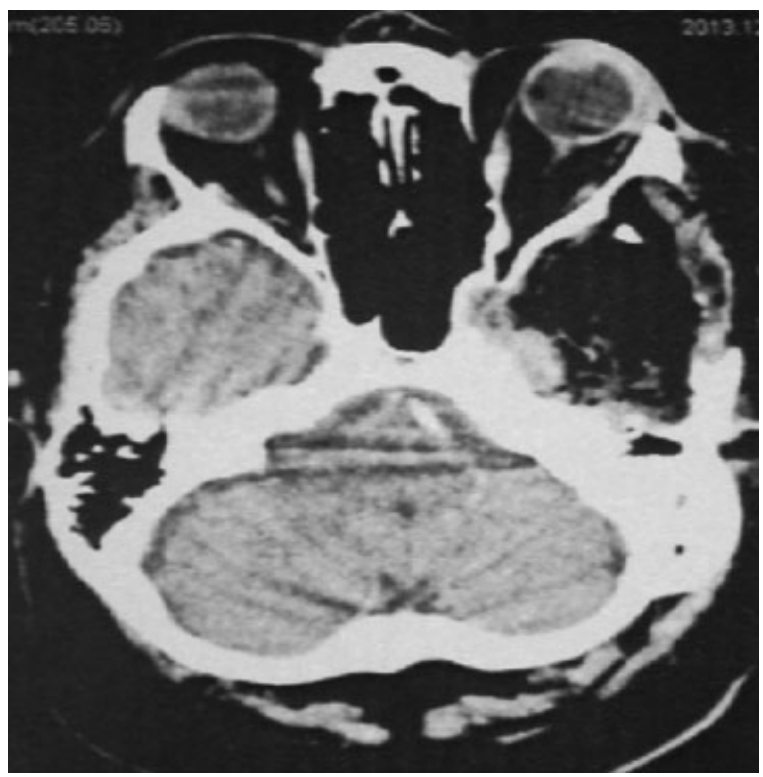

Fig. 2 TC de crânio em corte axial, pós-operatória, evidenciando ressecção de lesão expansiva em fossa média craniana esquerda.

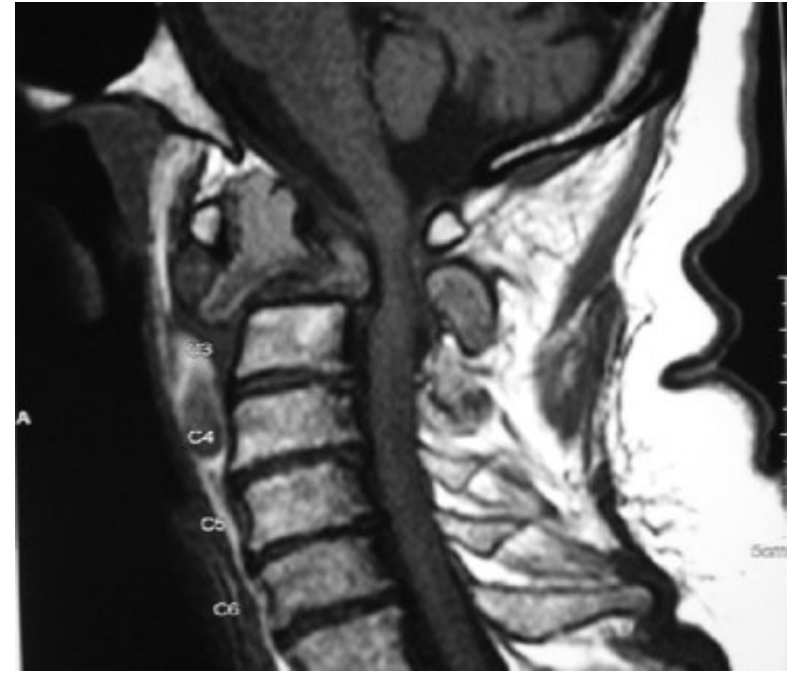

Fig. 3 RM da coluna cervical em corte sagital, com fratura patológica de C2 e compressão medular.

definição de foco primário. Submetida à ressecção transoral de C2 e fixação occipitocervical Oc-C5 (-Fig. 4). Seguimento hemato-oncológico com quimioterapia. Após 60 dias, apresentava melhora gradual da força motora - escala de rendimento de Glasgow 4.

\section{Discussão}

A incidência do MM aumenta com a idade, assim como o plasmocitoma; no entanto, o MM é menos proeminente em idades mais avançadas. ${ }^{3}$ Aproximadamente $90 \%$ dos casos de MM acontecem acima dos 50 anos. ${ }^{12}$ Os homens são mais comumente afetados do que as mulheres, e os negros apresentam incidência quase 2 vezes maior que os brancos. ${ }^{13}$ No momento do diagnóstico de MM, a média de idade é de 69

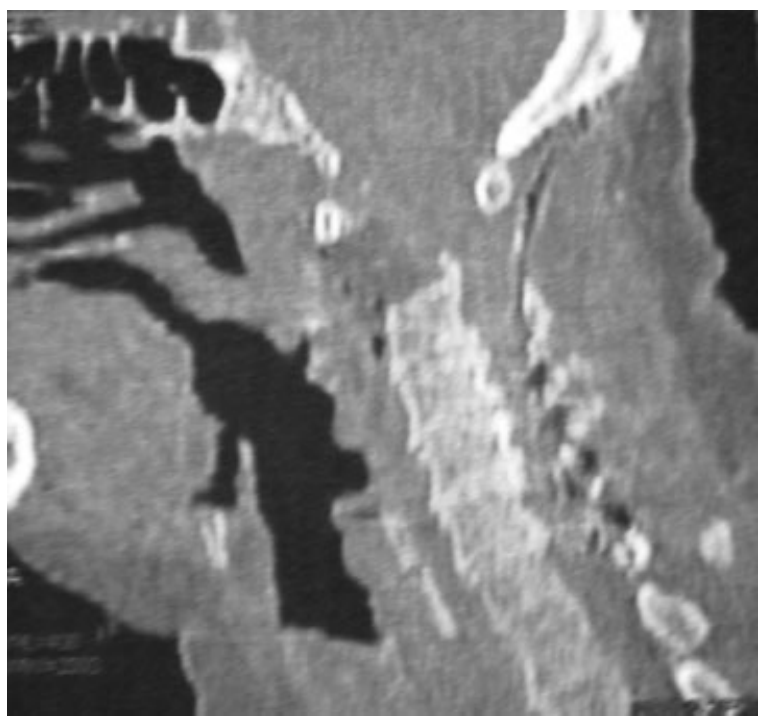

Fig. 4 TC da coluna cervical em corte sagital, após ressecção transoral de C2 e instrumentação occipitocervical. 
anos. $^{7}$ A idade dos pacientes, em ambos os casos, é semelhante à encontrada na literatura.

As manifestações clínicas surgem em decorrência de infiltração nos órgãos, principalmente os ossos, de plasmócitos neoplásicos, de produção de imunoglobulinas em excesso e da supressão da imunidade humoral normal. Como consequência, observa-se anemia grave, lesão óssea, insuficiência renal ${ }^{7,14}$-devido a precipitação de cadeias leves monoclonais nos túbulos coletores e distais e a hipercalcemia ${ }^{15}$-e infecção recorrente - devido a deficiência de imunoglobulinas normais e neutropenia. ${ }^{16}$ Destruição óssea é a principal manifestação clínica observada no mieloma múltiplo e no plasmocitoma, ${ }^{17}$ sendo a dor óssea o sintoma mais comum $^{6}$ logo, o padrão-ouro na avaliação inicial dos pacientes, utilizado no mundo todo, é a radiografia convencional. ${ }^{17,18}$ Nos casos aqui relatados, ambos os pacientes apresentam comprometimento ósseo. No caso 1, o quadro clínico decorrente da localização da massa tumoral ocasiona surdez e paralisia facial à esquerda - quadro clínico incomum em neoplasias plasmocitárias.

Radiologicamente, o MM traduz-se na presença de múltiplas lesões líticas no esqueleto, detectáveis em quase $80 \%$ dos pacientes no momento do diagnóstico, ${ }^{19}$ com severa desmineralização óssea - derivada da ativação de osteoclastos pelos plasmócitos neoplásicos ${ }^{20}$-apresentando-se, na globalidade dos casos, como uma doença osteodestrutiva generalizada que pode acometer qualquer osso. No entanto, há predomínio na coluna vertebral, nas costelas, no crânio, pelve e fêmur. ${ }^{5}$ Há dois padrões de envolvimento ósseo diferenciados no MM. Um caracterizado por lesões focais com confirmada infiltração de células plasmáticas circunscritas à medula óssea que pode levar à destruição interna do osso cortical. $O$ outro padrão caracteriza-se por uma infiltração difusa da medula óssea que conduz a uma mistura de células hematopoiéticas e células monoclonais fisiológicas, enquanto o tecido esponjoso do osso permanece basicamente intacto. Esses dois padrões de envolvimento do MM podem ocorrer isolados, sincrônicos ou metacrônicos. Além disso, o envolvimento de órgãos e/ou tecidos moles pode ser observado; ele pode originar-se de lesões primordialmente extraósseas ou surgir secundariamente a partir de lesões ósseas após a destruição do osso cortical. ${ }^{11}$ Em consonância com a literatura, nos dois casos apresentados, as lesões ocorrem em locais comuns de acometimento do mieloma, mas não se observou infiltração difusa da medula óssea. No caso 1 , observou-se comprometimento extraósseo; no caso 2, o paciente, quando diagnosticado, já possuía fratura em C2.

$\mathrm{Na}$ prática clínica, quando no mínimo dois dos três critérios a seguir estão presentes, pode ser realizado o diagnóstico de MM: (1) lesões ósseas; (2) presença sérica ou urinária de imunoglobulina monoclonal (proteína $\mathrm{M}$ ); e (3) excesso de plasmócitos na medula (geralmente acima de $10 \%) .{ }^{7,16}$ Estes achados não devem derivar de um carcinoma metastático, de doenças do tecido conjuntivo, de infecções crônicas ou de linfoma. ${ }^{15}$

O tratamento do mieloma múltiplo deve ser iniciado imediatamente em pacientes sintomáticos que demonstrem lesões orgânicas. ${ }^{7}$ Já nos pacientes assintomáticos, não se verificou melhora adicional quando o tratamento foi iniciado diante do diagnóstico. ${ }^{7}$

O tratamento do MM varia muito com a faixa etária do paciente. 0 transplante heterogêneo de medula óssea foi o tratamento que apresentou maior sobrevida, mas é limitado pelo pouco número de doadores compatíveis. ${ }^{16}$ Se o paciente tiver menos de 70 anos, o transplante autólogo de célulastronco do sangue periférico com quimioterapia convencional obtém uma sobrevida média superior à alcançada pela quimioterapia convencional isolada. ${ }^{15}$

A quimioterapia é o tratamento inicial de eleição para o mieloma múltiplo sintomático nos pacientes com mais de 70 anos ou nos pacientes mais jovens, nos quais o transplante é inexequível. $^{15}$

A radioterapia paliativa deve ser restrita aos pacientes portadores de MM com dor incapacitante e um processo focal bem definido que não respondeu à quimioterapia. ${ }^{15}$

Concomitantemente ao tratamento convencional, é feita uma terapia de suporte visando a anemia (eritropoietina) e a prevenção de fraturas (bifosfonados, coletes etc.). ${ }^{6}$

Até este momento, o MM é incurável ${ }^{9,21}$ e apresenta baixa sobrevida, ${ }^{6}$ podendo variar de alguns meses a vários anos, ${ }^{22}$ sendo a sobrevida média de aproximadamente 3 anos. ${ }^{15}$ Embora seja doença de origem hematológica, a mesma pode apresentar repercussão neurológica com necessidade de terapia cirúrgica. Assim, deve fazer parte do diagnóstico diferencial na prática neurocirúrgica.

\section{Referências}

1 Cardoso I, Secioso P, Moreira M. Plasmocitoma solitário ósseo. Relato de caso. Rev Bras Clin Med 2010;8(2):183-186

2 Jawad MU, Scully SP. Skeletal Plasmacytoma: progression of disease and impact of local treatment; an analysis of SEER database. J Hematol Oncol 2009;2(2):41

3 Kilciksiz S, Karakoyun-Celik O, Agaoglu FY, Haydaroglu A. A review for solitary plasmacytoma of bone and extramedullary plasmacytoma. ScientificWorldJournal 2012;2012:895765

4 Dimopoulos MA, Moulopoulos LA, Maniatis A, Alexanian R. Solitary plasmacytoma of bone and asymptomatic multiple myeloma. Blood 2000;96(6):2037-2044

5 FILIPE. Joana et al. Mieloma múltiplo no diagnóstico diferencial de patologia do seio esfenoidal - Caso clínico. In: CONGRESSO NACIONAL DE OTORRINOLARINGOLOGIA E CIRURGIA CÉRVICO-FACIAL, 57, 2011, Lisboa. Anais. Lisboa: Congresso Nacional de Otorrinolaringologia e Cirurgia Cérvico-facial; 2011. p. 1-5.

6 Klaus DG, Carvalho DC, Baldessar MZ. Caso clássico de mieloma múltiplo: uma revisão. Artigo de Revisao 2009;38(4):110-113

7 Palumbo A, Cerrato C. Diagnosis and therapy of multiple myeloma. Korean J Intern Med 2013;28(3):263-273

8 Silva ROP, Brandão KMA, Pinto PVM, et al. Mieloma múltiplo: características clínicas e laboratoriais ao diagnóstico e estudo prognóstico. Rev Bras Hematol Hemoter. 2009;31(2):63-68

9 Cömert M, Güneş AE, Sahin F, Saydam G. Quality of life and supportive care in multiple myeloma. Turk J Haematol 2013; 30(3):234-246

10 Hungria VTM, Maiolino A. Mieloma múltiplo: progressos e desafios. Rev Bras Hematol Hemoter 2007;29(1):1-2

11 Derlin T, Bannas P. Imaging of multiple myeloma: Current concepts. World J Orthod 2014;5(3):272-282 
12 Andrade VP. Aspectos morfológicos da infiltração da medula óssea por condições exibindo diferenciação plasmocitária e gamopatia monoclonal. Rev Bras Hematol Hemoter. 2009; 31(4):273-279

13 Longo et al. Medicina Interna de Harrison. 18 ed. Porto Alegre: Artmed; 2013

14 Saini N, Mahindra A. Therapeutic strategies for the treatment of multiple myeloma. Discov Med 2013;15(83):251-258

15 CECIL. Russell L. Cecil medicina. 23. ed. Rio de Janeiro - RJ. Editora Elsevier, 2009.

16 Sucro LV, Silva JCML, Gehlen GW, Eldin JFS, Amaral GA, Santana MAP. Mieloma múltiplo: diagnóstico e tratamento. Rev Med Minas Gerais 2009;19(1):58-62

17 Hungria V. Doença óssea em mieloma múltiplo. Rev Bras Hematol Hemoter. 2007;29(1):60-66
18 Martinez GA. Fatores prognósticos no mieloma múltiplo. Rev Bras Hematol Hemoter 2007;29(1):27-30

19 Palumbo A, Anderson K. Multiple myeloma. N Engl J Med 2011; 364(11):1046-1060

20 Áster JC. Doença de leucócitos, linfonodo, baço e timo. In: Kumar V, Abbas Ak, Fausto N. Robbins e Cotran. Patologia - Bases patológicas das doenças. $7^{\mathrm{a}}$ ed. Rio de Janeiro: Elservier; 2005: 695-746

21 Avanzi O, Landim E, Meves R, Caffaro MFS, Pellegrino LAN. Mieloma múltiplo da coluna: avaliação do tratamento cirúrgico. Coluna/Columna 2009;8(3):254-259

22 Chauffaille MLLF, Yamamoto M, Rodrigues MM, et al. Elevada incidência de anormalidades cromossômicas numéricas detectadas por FISH multicentromérico em pacientes com mieloma múltiplo. J Bras Patol Med Lab 2007;43(1):17-23 